Stephen H. Rolbin MDCM FRCPC, Ernest Hew MD fRCPC FFarcs(1), Gina Ogilvie

\title{
A comparison of two types of epidural catheters
}

The purpose of this study was to compare two epidural catheters - the Portex epidural catheter and Vas-Cath ${ }^{3}$ catheter. One hundred and fifty patiens in labour who received epidural anaesthesia were selected and either one or the other catheter was used, based on random assignment. Ease of insertion, maintenance and removal of the catheter were assessed, as was the incidence of blood return and paraesthesiae during epidural catherer insertion. There were no signiftumt differences between the catheters as far as insertion, maintenance and removal were concerned. However, the incidence of paresthesiae was 44 per cent with the Portex ${ }^{(1)}$ and 24 per cent with Vas-Cath ${ }^{\oplus}$ catheters $(\mu<0.008)$. The incidence of bloud vessel trauma was 12 per cent with the Portex and 6.7 per cent with the Vas-Cath catheter $(p=N S)$. Choice of epidural catheter is a factor to be considered in minimizing the incidence of bload vessel tratoma or paresthesiae.

Continuous cpidural anacsthesia is the most common anaesthetic technique used in obstetrics. However, the use of epidural catheters are associated with complications. The insertion of the catheter may be associated with the presence of blood in the catheter or nerve root irritation. ${ }^{1-3}$ Recent data from our hospital documented a 30 per cent incidence of paresthesiae and a ten per cent incidence of blood returning after insertion of an epidural catherer. $^{4}$

Various techniques have been used to reduce the incidence of these complications. The injection of $10 \mathrm{ml}$ of a local anaesthetic ${ }^{5}$ prior to the insertion of the epidural catheter decreased the incidence of blood vessel puncture and the injection of $10 \mathrm{ml}$ of air $^{6}$ was shown to be

\section{Key words}

ANAESTHESIA: obstetric; ANAESTHETIC TECHNIQUES, REGIONAL: epidural; EQUIPMENT: epidural catheters; COMPLICATIONS: paresthesia, bleeding.

From the Department of Anaesthesia, Mount Sinai Hospital, University of Toronto, Toronto, Ontario.

Address correspondence to: Dr. S. Rolbin, Department of Anacsthesia, Mount Sinai Hospital, 600 University Avenue, Toronto, Ontario, Canada, M5G 1 X5. associated with a decreased incidence of paresthesiae. However, both these techniques may introduce their own problems. The use of air during epidural anaesthesia has been advocated ${ }^{7}$ but may prevent uniform spread of the block, and vascular air embolism may occur. ${ }^{8}$ In addition, injection of $10 \mathrm{ml}$ of a local anaesthetic agent, prior to insertion of the epidural catheter may cause systemic toxicity if injected intravascularly or subarachnoid block if the dura was punctured.

\section{Methods}

The intention of this study was to evaluate two types of catheters. We compared the commonly used 19-gauge Portex ${ }^{(8)}$ epidural catheter (model No. 389300), which is made of nylon and has a blunt end and three side-holes near the catheter tip, with the 19 gauge Vas-Cath ${ }^{\circledR}$ epidural catheter (model no. ECC-19), which is made of clear polyurethane, with a radio opaque stripe and a blunt end with three side-holes near the tip. Both products were commercially available in Canada at the time of the study.

This study was approved by the Human Subjects Review Committee of the University of Toronto. Informed consent was obtained from each patient.

One hundred and fifty patients in labour, who requested continuous epidural anaesthesia, were selected and randomly assigned to receive one of the catheters. The epidural space was identified using the loss of resistance technique with a $16 \mathrm{~g}$ Tuohy needle and a $5 \mathrm{ml}$ syringe with less than $3 \mathrm{ml}$ of air. The catheter was inserted before injection of local anaesthetic. The procedures in both groups were done by staff andesthetists or fourth-year anaesthesia residents. The catheters were inserted $4-5 \mathrm{~cm}$ into the epidural space.

The ease of insertion of the catheter was judged by an independent observer for the presence or absence of resistance to insertion. There was only one observer for all the patients. This observer also documented the presence or absence of blood return in the catheter and of paresthesia on insertion of the catheter. Blood retum was tested for by checking for spontaneous return of blood and with negative pressure applied to the catheter. If the patients did not volunteer the symptoms of paresthesiae, the observer then asked the patient directly. In addition, the observer noted the occurrence of problems with the 
TABLE I Patient Groups

\begin{tabular}{|c|c|c|}
\hline & Portex Catheter & $V_{a s}-C_{a t h}$ Catheter \\
\hline Number of patients & 75 & 75 \\
\hline Primipara & 48 & 44 \\
\hline Multipara & 27 & 31 \\
\hline Height $-\mathrm{cm}$ & $161.4 \pm 7.11$ & $160.3=6.98$ \\
\hline Weight - kg & $75.5 \pm 12.11$ & $74.1 \pm 10.18$ \\
\hline
\end{tabular}

catheter when used for repeated doses during the course of labour and delivery. The results were analyzed statistically using binomial comparisons with a normal approximation.

\section{Results}

There were 75 patients in each group. There were no statistically significant differences in height, weight or parity between the two groups assessed (Table I). The occurrence of blood return and paresthesiae associated with epidural catheter placement are shown in Table II. The incidence of paresthesiae was 44 per cent with the Portex ${ }^{3}$ catheter and 24 per cent with the Vas-Cath catheter $(\mathrm{p}<0.008)$

The patients in whom the Portex cathelers were used received an average of $1.7 \pm 1.0$ doses through the epidural catheter. This compares with $1.75 \pm 1.1$ for the Vas-Cath catheters ( $\mathrm{p}=\mathrm{NS}$ ). The duration of the epidural catheter retention in situ was $285 \pm 149$ minutes for the Portex ${ }^{\text {Bg }}$ catheters and $277 \pm 149$ minutes for the Vas-Cath ${ }^{\text {os }}$ catheters.

There were no significant differences between the groups with respect to obstruction of the catheter for subsequent doses, kinking of the catheter or difficultics in removal.

\section{Discussion}

Transient neurologic deficits are known to occur after lumbar epidural analgesia. ${ }^{9,10}$ These symptoms might be secondary to trauma to nerve roots and blood vessels by the epidural catheter during insertion or removal. Our study compared two catheters, one nylon and the other high grade polyurethane. The polyurethane catheter felt much softer than the one made of nylon.

TABLE II Occurrence of blood return and paresthesiae during epidural catheter placement

\begin{tabular}{llll}
\hline & $\begin{array}{l}\text { Portex }^{\text {Do }} \\
\text { Catheter }\end{array}$ & $\begin{array}{l}\text { Vas-Cath } \\
\text { Catheter }\end{array}$ & Significance \\
\hline Number of patients & 75 & 75 & \\
Thrcaded easily & 69 & 70 & NS \\
Blood in catheter & 9 & 5 & NS \\
Paresthesia & 33 & 18 & $p<0.008$ \\
\hline
\end{tabular}

The ease of insertion of the catheter and acceptability for repeat doses during labour and delivery was the same in both groups. The incidence of vascular cannulation of 12 per cent with the Portex ${ }^{\text {in }}$ catheter and 6.7 per cent with Vas-Cath ${ }^{*}$ catheter $(p=N S)$ is comparable with previous studies. $^{5,6}$ It is particularly important to note that the epidural catheter was inserted before any local anaesthetic agent. This permitted us to injcet the cntire dose of anaesthetic through the epidural catheter and thus test it for inadvertent vascular or subarachnoid placement. A test dose using $3 \mathrm{ml}$ of 0.5 bupivicaine with 1:200,000 epinephrine was then administered.

No permanent neurologic sequelae occurred in our study but the decrease in the incidence of paresthesiae from 44 to 24 per cent was highly significant. Since the presence of paresthesiae might correlate with the occurrence of neurologic sequelae and there appears to be no disadvantages to the polyurethane catheter, this catheter (Vas-Cath ${ }^{(8)}$ is now wur catheter of choice. The only major objection to the Vas-Cath catheter was lack of clarity in the catheter due to the radio-opaque stripe. This has been corrected by the manufacturer and completely clear catheters are now available.

Previous reports to reduce the incidence of vessel puncture or paresthesia on insertion of the epidural catheter have suggested using either $10 \mathrm{ml}$ of local anaesthetic or air prior to insertion of the catheter. ${ }^{5,6}$ Neither of these methods is without potential problems. By using an epidural catheter made of polyurethane, rather than nylon, this study has found a similar reduction of these complications.

It is important to limit the number of catheter insertions. If a second catheter is inserted near the site of a previous vessel perforation, then the risk of injecting local anaesthetic intraveascularly may be increased. This is one of the reasons why many authorities recommend giving a test dose through the catheter and injecting the remainder of the dose slowly, pausing every $5 \mathrm{ml}$ in order to test for systemic toxicity. ${ }^{11}$ The appropriate use of test doses remains controversial, and is not addressed in this study. The anaesthetist must remain vigilant for the possibility of inadvertent intravascular or subarachnoid injection at the times of subsequent doses of locl anaesthetic.

\section{References}

1 Bromage PR. Epidural Analgesia, Philadelphia: W.B. Saunders, 1978 , p. 29

2 Moir DD, Carty MJ. Obstetric Anaesthesia and Analgesia, London: 2nd edition, 1980, p. 207.

3 Crawford JS. Principles and Practice of Obstetric Anaesthesia, 4th edition, Oxford: Blackwell Scientific Publications, 1978 , p. 171

4 Rolbin SH, Relle A, Hew EM. Hyperventilation docs not 
affect the incidence of paresthesiae and blood vessel cannulation during epidural catheter insertion. Can Anaesth Soc J 1985, 32: 568.

5 Verniquet $A J W$. Vessel puncture with epidural catheters. Anaesthesia 1980, 35: 660-2.

6 Philip $B K$. Effect of epidural air injection on catheter complications. Regional Anesthesia 1985, 10: 21-3.

7 Laman EN, McLeskey CH. Supra-c]avicular subcutaneous emphysema following lumber epidural anesthesia. Anesthesiology 1978, 48: 219-21.

8 Naulty SJ, Ostheimer GW. Datta S, Krapp R, Weiss JB. Incidence of venous air embolism during epidural catheter insertion. Anesthesiology 1982, 57: 410-2.

9 Ballin NC. Paraplegia following epidural analgesia. Anaesthesia 1981, 36: 952-3.

10 Kane RE. Neurologic deficits following epidural or spinal anesthesia. Anesth Analg 1981, 60:150-61.

11 Shnider SM, Levinson $G$. Anesthesia for Obstetrics, 2nd edition, Baitimore: Williarns and Wilkins, 1981, p. 161 I.
Résumé

Le but de cette étude était de comparer deur carhéters périduraux - le Ponex et le Vas-Cath. On a installé de façon aléatoire l'un ou l'autre des cathéters chez 150 patientes en travail qui recevaient une anesthésie péridurale. On a évaluê la facilité d' insertion, le maintien es le retrait du cathéter ainsi que l'incidence du retour sanguin et de la paresthésie durant l'insertion du cathéter péridural. Aucune différence significative n' existait entre les cathéters quant à l'insertion, le maintien et le retrait. Cependan, l'incidence de paresthésie étair de 44 pour cent avec le Portex et de 24 pour cent avec le Vas-Cath $(p<0.008)$. L'incidence de traunatisme au vaisseau sanguin érait de 12 pour cent avec le Portex et de 6.7 pour cent avec le Vas-Cath ( $p=N S$ ). Le choix du cathéter péridural est unfacteur à considérer afin de minimiser l'incidence de traumatisme vasculaire et de paresthésie. 